\title{
CONFIGURACIÓN Y CONSTELACIÓN: ALGUNAS REFLEXIONES SOBRE EL POTENCIAL DE UNOS ESTUDIOS TRANSANDINOS
}

\author{
POR \\ Pablo Valdivia Orozco \\ Europa-Universität Viadrina Frankfurt/Oder
}

Hablar de estudios transandinos se me hace tan poco evidente, tanto en lo que se refiere al término como al proyecto, que creo merece algunas reflexiones sobre el estatus histórico y epistémico de lo que podrían ser unos tales estudios. No es pérdida de tiempo ser explícito en este asunto, porque, como sucede con todo nombre, no se trata de una simple cuestión de denominación; todo renombramiento implica igualmente una política (deseada o no) en las prácticas de nuestros saberes.

Antes de entrar en detalles, ya es posible problematizar una primera pregunta que aparece si nos preguntamos dónde y cómo ubicar los estudios transandinos, puesto que el giro que denominan presupone necesariamente unos estudios andinos. Si no es superfluo distinguir entre estudios andinos y transandinos por un lado y si, por otro lado, lo transandino no sustituye lo andino: ¿cuál es su relación? ¿Es una culminación? ¿Se inscriben los estudios andinos en un giro "trans"? ¿O se trata más bien de algo que se articula desde los mismos estudios andinos, algo que desde su mismo trabajo se hace necesario sin necesariamente ser la suma de ello? Supongo que es preferible el segundo escenario, aunque no hay que perder de vista que siempre, hasta cierto punto, los estudios se inscriben en algo más, en algo que no necesariamente corresponde a la lógica de su objeto de estudio, en un discurso del saber que siempre obedece a desafíos que no necesariamente se deben al objeto de estudio.

Para entrar en materia de manera más concreta, propongo partir con una breve lectura de dos textos de Antonio Cornejo Polar. Espero poder así construir un contexto y un debate histórico para discutir en qué sentido y por cuáles razones específicas es prometedor considerar un proyecto como los estudios transandinos. Los dos textos son "Literatura peruana: Totalidad Contradictoria" de 1983 y el breve aunque esencial texto "Para una teoría literaria hispanoamericana: a veinte años de un debate decisivo" de 1992, aunque publicado póstumamente en 1999. 
Hablando de "trans", creo que el término de totalidad, y más específicamente el de totalidad contradictoria, que se refiere tanto a la construcción de un canon literario nacional como a las aspiraciones más altas de la reflexión teórica, marcan bien el problema que a lo mejor hizo surgir la búsqueda de nuevos términos, nuevos enfoques, de algo que a lo mejor lo transandino se propone abarcar. La totalidad contradictoria es una especie de "trans", sin duda.

Es importante notar que justo en esos años, cuando Cornejo Polar escribe este texto, ya se puede constatar el establecimiento de los estudios de minorías, de estudios fronterizos como los de la literatura chicana y, ante todo, ya existe un corpus teórico bastante bien definido de lo que se podría nombrar el paradigma caribeño, en particular en su expresión neobarroca. El mismo Cornejo Polar, en su texto sobre la teoría literaria hispanoamericana lo nota y nos recuerda - cosa que me parece en este contexto de importancia fundamental- desde cuál perspectiva comenta el surgimiento de estas revisiones teóricas y metodológicas: es el debate de los años setenta que se propuso "producir una teoría realmente nuestra" ("Para una teoría" 9) desde el cual Cornejo Polar enfoca esta revisión. Por muy obvio que parezca, es importante subrayar esta perspectiva, ya que se inscribe en otra historia y otra historicidad que la historia de los estudios culturales o las revisiones de la "agenda problemática de los noventa" (9). Es importante subrayar este hecho, porque a lo mejor la agenda de los noventa no necesariamente responde a los problemas que también se estuvieron debatiendo en los años setenta. La obvia crisis del objeto "literatura" a la cual se refiere Cornejo Polar (los debates de la literatura oral, chicana, etc., es decir los debates de inclusión y exclusión), sólo se refieren al quizás más accesible aspecto del problema: la pregunta del corpus. Queda por fuera el proyecto estrictamente teórico, el proyecto de una "teoría realmente nuestra" que ciertamente tuvo que fracasar al suponer que "la literatura latinoamericana era una y coherente" (9).

Ahora bien: esta pregunta no me parece el punto de partida de lo que podrían ser los estudios transandinos. No es -y Cornejo Polar es uno de los más destacados en afirmarlo- cosa de los años noventa darse cuenta que la literatura latinoamericana no se deja inscribir en un código único que su teoría luego tendría que articular. Me parece de mayor interés una problemática bastante opaca, difícil de descifrar que Cornejo Polar nos presenta como segundo y quizás más esencial problema, que no se deriva del diseño, sino del mismo discurso teórico. Volver al problema en su versión "literaria" es volver a un problema que para Cornejo Polar no se deja responder del todo con las políticas de la diferencia:

Por cierto, dicho todo lo anterior, se hace evidente otro problema: ¿cómo, con qué instrumentos, con qué arsenal metodológico enfrentamos a esta literatura compleja y heterogénea? Obviamente no tengo ninguna respuesta general $-\mathrm{y}$ me temo que simplemente no existe $[\ldots](11)$

Revista Iberoamericana, Vol. LXXXI, Núm. 253, Octubre-Diciembre 2015, 939-953 
Y luego concluye:

[...] pero un examen atento de la crítica hispanoamericana e hispanoamericanista última demostraría que cada vez que asumimos como punto de partida que nuestra literatura es muchas literaturas entre sí imbricadas, y a veces de manera belicosa, el pensamiento crítico encuentra caminos excepcionalmente creativos para dar razón no sólo de la heterogeneidad de la literatura latinoamericana sino también de esas muchas -todas las sangres que se entreveran entre nosotros, en nosotros, que tenemos la posibilidad de vivir en cada una de nuestras patrias, si vencemos el egoísmo, todas las patrias. (12, énfasis mío)

A lo mejor el proyecto de una "teoría realmente nuestra" también tuvo que fracasar por un cierto tipo de aspiración teórica. Si bien y justamente se criticó que las teorías no son neutras, no se supo problematizar bien la relación entre la teoría y "lo nuestro". Aún con el diseño justo -es decir, suponiendo que la literatura es heterogénea, etc.tenía que fracasar el proyecto por el simple hecho de ser una teoría y no una crítica. El espacio de lo "nuestro" es el espacio de la crítica y no necesariamente el espacio de la teoría. Y si, gracias a una teoría, será posible un día vivir todas las patrias en cada una de las nuestras, la relación de lo "nuestro" y la teoría no será una relación de correspondencia o identidad. Es decir: una teoría "realmente nuestra", en cuanto teoría, requiere siempre algo que no es totalmente nuestro, requiere dar otro paso que el de la crítica. Por eso mismo (y eso me parece de particular interés y representa sin duda una dimensión crítica que creo hasta hoy en día sigue vigente), también una teoría de la diferencia tenía que fracasar como teoría, siendo en el fondo una crítica. ¿Cuál, pues, es el problema de la teoría, y específicamente de la teoría literaria? ¿A qué se refiere Cornejo Polar al sugerir esta diferencia entre teoría y crítica? ¿Por qué no contentarse con una crítica de la diferencia?

Quiero, sin duda de manera previsible, tratar estas dos referencias de teoría y crítica como la diferencia que se puede formular entre estudios transandinos y estudios andinos. Es en ese sentido de crítica que quiero insistir en que los estudios transandinos no han de sustituir los estudios andinos y es en ese sentido, como respuesta a una problemática de la misma teoría, que debe articularse una propuesta transandina como un aporte a la teoría, como una teoría que no reproduce los mismos errores de la teoría globalizante que tuvo que fracasar (y eso independientemente de cuál sea su diseño), sino una teoría que es "nuestra", no porque se ocupa de "nuestros" objetos o "nuestra" diferencia, sino por ser nuestro aporte al discurso teórico y que como tal nos permite pensar con una patria todas las patrias.

Antes de volver a esta idea de una patria que permite pensar todas las patrias y la por supuesto urgente pregunta sobre qué puede significar tal frase en un contexto andino, quiero proponer otra perspectiva teórica que Cornejo Polar expone en su texto

Revista Iberoamericana, Vol. LXXXI, Núm. 253, Octubre-Diciembre 2015, 939-953 ISSN 0034-9631 (Impreso) 
sobre la literatura peruana como totalidad contradictoria. Aquí el proyecto de una teoría (literaria) no es visto con tanto pesimismo y ya veremos por qué. Antes de todo, se hace notorio que este texto concluye con la misma, implícitamente citada frase de Arguedas que cierra el texto sobra la teoría literaria latinoamericana. Me parece en todo caso llamativo que sea justamente el concepto de totalidad y más precisamente de una totalidad contradictoria, el que le permite formular un plano teórico. Escribe Cornejo Polar en 1983:

\begin{abstract}
Interesa entonces adoptar una perspectiva y articular categorías teóricas con conocimientos históricos. Se burlan así los riesgos de la falsa neutralidad, pues asumir un tiempo es asumir también su conflictividad social, a la par que se alejan los peligros del idealismo y del empirismo, peligros que, tratándose del estudio de una literatura nacional, implican en el primer caso la esencialización de sus dos términos, como si la literatura no fuera cambiante y la nación una fluencia continua, y en el segundo la simple recopilación de datos sin sentido orgánico ni procesal. Es en el espacio formado por la relación dialéctica entre teoría e historia donde debe fundarse una nueva concepción de la literatura peruana. A colaborar en este esfuerzo, que sin duda tendrá que ser colectivo, están destinadas las siguientes reflexiones. ("La literatura peruana”38)
\end{abstract}

Aquí no sólo la teoría es posible, sino además necesaria. Leamos que se propone una teoría de la totalidad contradictoria de la literatura peruana. Bajo el subtítulo "La categoría de totalidad: teoría e historia" afirma Cornejo Polar:

En la crítica central al concepto de pluralismo subyace una opción teórica que debe exponerse, siquiera someramente, en sus puntos fundamentales. [...] No esta demás señalar que concluido el auge de la crítica inmanentista, se reabre en óptimas condiciones la posibilidad de entender que ese proceso productivo, incluyendo su etapa de recepción, es el verdadero objeto de la disciplina literaria (38-39)

Es aquí que opera el concepto de totalidad contradictoria, como alternativa a la unidad plural. Totalidad es entonces aquella categoría que permite pensar una entidad teórica en una constelación histórica específica y debatir sus diferentes interferencias sin que su integración se inscriba en la problemática agenda de unificación (programática) o diferencia (siempre empírica). El caso paradigmático para ese concepto de totalidad es -nada sorprendente- la literatura colonial (46). Ahora, la integración -hecho de importancia eminente-dentro de lo total o mejor dicho, dentro del plano teórico, permite pensar no sólo contradicciones fundadoras de una sociedad en constante cambio, es decir, exponer una contradicción específica de un contexto o una obra específicos, sino además, reunir versiones contradictorias. Es en este momento que el enfoque crítico de lo que serían los estudios andinos pasa a ser una propuesta teórica transandina, ya

Revista Iberoamericana, Vol. LXXXI, Núm. 253, Octubre-Diciembre 2015, 939-953 
que esa variedad de versiones requiere otro plano que va más allá del camino creativo de la crítica. Cito en extenso:

No se trata, empero, de la yuxtaposición de dos corpus literarios ligados sólo por la identidad de sus referentes generales; ni siquiera, en el fondo, de la articulación de ambos mediante un sistema especular inverso que evidencie las contradicciones de dos conciencias convergentes en la insolitud de su mutuo descubrimiento. Aunque este segundo procedimiento es necesario, pues fija el tramado sobre el que se dibujan los distintos sistemas simbólico-estéticos, la crítica sólo se legitima como tal en cuanto pueda dar razón de la especificidad de éstos y de sus también específicas contradicciones. Después de todo ni la literatura hispánica ni la literatura indígena por separado, pero tampoco la confluencia de ambas en un espacio sin formalización estética, corresponden verdaderamente al objeto que se denomina literatura de la Conquista. Tal objeto espera aun un afinamiento teórico. (46)

La misma noción de una literatura de la Conquista, "disgregada y heteróclita como ninguna" (45), presupone una construcción teórica que requiere de otra respuesta que la respuesta crítica. Es el nivel teórico el que hace necesario hablar de totalidad en vez de unidad. Al mismo tiempo, la categoría de totalidad no se limita a ser una propuesta teórico-metodológica, sino que, además, requiere un carácter político, si no es que utópico. Cierra Cornejo Polar su texto con las palabras:

En este sentido la literatura nacional peruana no sólo es testimonio de lo que Basadre llamo "la vida peruana", a la que sin duda reproduce en el nivel y con los atributos que le son propios; es esa misma vida, que ahora sabemos múltiple, plural y heteróclita, hecha paradójicamente a fuerza de oposiciones y conflictos dramáticos e incluso sangrientos, hasta que en algún momento la totalidad nacional no sea el resultado de las contradicciones sino de la justicia fraternal e integrador: cuando se cumpla la bellísima profecía de José María Arguedas y “en nuestra patria (...) cualquier hombre no engrilletado ni embrutecido por el egoísmo, pued(a) vivir, feliz, todas las patrias”. (50)

Otra vez este vivir todas las patrias, aunque ahora desde la perspectiva de una totalidad utópica.

Ahora bien, pese a la supuesta promesa conciliadora de este párrafo, quiero señalar que la totalidad, en nuestra condición actual, aún no es aquella vida de justicia fraternal, sino una totalidad de conflictos, un conflicto sangriento y uno de diferentes versiones y revisiones. Es difícil imaginar cómo es posible dar ese paso en la práctica. Y sin embargo, algo aventurado quizás, quiero proponer una lectura de esta promesa algo utópica como un paso que debemos dar, al menos, en nuestra teoría. Se trata, entonces, de formular y pensar una generalidad teórica desde lo andino que no es la teoría de su diferencia ni de su unidad, sino de su experiencia contradictoria que, como teoría de

Revista Iberoamericana, Vol. LXXXI, Núm. 253, Octubre-Diciembre 2015, 939-953 
una totalidad contradictoria, para nada tiene que limitarse a los objetos estrictamente andinos, sino que como tal es un aporte teórico, "nuestro" aporte.

Para esclarecer de lo que se trata y a modo de precisar un proyecto que llevo desarrollando ya hace un buen tiempo (Valdivia Orozco, "Configuraciones del convivir"), quiero ofrecer dos términos alternativos a lo que Cornejo Polar nombraba crítica y teoría, la especificidad y la totalidad de la literatura. Ubicando el plano de la crítica (literaria) que trata el problema de inclusión y exclusión gracias a sus lecturas concretas de un texto y que va construyendo vía sus lecturas un corpus específico, propongo denominar este plano con el término de configuración. Obviamente, no podemos renunciar a este plano, no podemos dejar de leer y eso significa: ejercer relaciones de inclusión y exclusión, fundamentar "figuraciones".

Para el plano de la teoría como totalidad contradictoria propongo el término de constelación, nombre que obviamente cita la primera lectura estríctamente teórica: la lectura de las constelaciones estelares (Blumenberg). Aunque parezca muy cercana a la propuesta de Walter Mignolo de diferenciar entre el canon y el corpus, quiero subrayar que se trata de otra pregunta: no son los mecanismos de un discurso de integración y exclusión que se oponen a la real productividad del corpus los que me interesan al formular esta diferencia, sino más bien el valor teórico de nuestras lecturas críticas, el aporte de ellas a lo que podría ser una teoría más allá de la unidad y la diferencia. Pensada la teoría como constelación, algo que desde luego siempre se puede y debe revisar según las configuraciones que trabajamos, implica pensar una totalidad que no sólo no niega lo específico, sino que, más bien, es únicamente posible de formular porque partimos de una historia concreta, sin que esta se realice o culmine en teoría. Es decir: no sólo se trata de debatir sobre cuáles obras entran o no como ejemplos paradigmáticos, no sólo se trata de revisar los discursos por diferentes expresiones y particularidades - eso sin duda es importante y no pierde nada de su importancia-, sino además de insistir en la teoría como totalidad contradictoria que por ello no es una figuración de algo, sino una toma de posición, una construcción. Es así que se puede hacer teoría y al mismo tiempo mantener una especificidad que no la convierte en una práctica de exclusión o gnosis. La teoría pensada como constelación no necesariamente tiene que inventar nuevos términos y nuevas entidades -como lo fue el caso de la literatura latinoamericana-, sino que los especifica sin regionalizarlos, los confronta con lecturas específicas sin subjetivar su articulación. Se trata, en pocas palabras, de revisar y diferenciar las relaciones que se producen en nociones dicotómicas como la de "lo general" y "lo específico" o "lo global" y "lo local", para sólo nombrar las más importantes.

La diferencia de configuración y constelación me permite entonces, primero, formular la diferencia entre lo andino y lo transandino en otros términos y ante todo evitar una relación de superación o posterioridad. Segundo, me permite, en contra de

Revista Iberoamericana, Vol. LXXXI, Núm. 253, Octubre-Diciembre 2015, 939-953 
la fácil crítica de una noción de literatura como elitista, mostrar cómo la literatura o mejor dicho, su particular historicidad de permanente revisión, puede ser un caso paradigmático para disputar estas problemáticas. Ciertamente no estoy pensando en una noción excluyente de literatura. Me interesa más bien subrayar que no es vano que los estudios literarios, en los años noventa tan criticados, son los que nos pueden ofrecer herramientas importantes para concebir lo que es teoría como una totalidad específica, una totalidad que sin excluir especificidades no se limita únicamente a generalizar lo específico. Y ciertamente, todo esto es una reformulación un poco burda de lo que Arguedas expresó con su utopía de vivir en una patria todas las patrias. No obstante, al posible optimismo que se pueda hallar en esta frase, es necesario advertir que ella excluye implícitamente la frase de que una patria es todas las patrias.

¿Cómo concretar estas preguntas de una dimensión tan extensa? Creo que es legítimo considerar estas preguntas desde una perspectiva americanista muy concreta y ubicar su inicio en el problema de la traducción tal como se nos presenta en "nuestra" América, noción que desde siempre incluye y presupone una situación colonial. Contamos con (al menos) dos escenas de la traducción en la conquista, a las cuales podemos atribuir un valor paradigmático, si no mítico: me refiero a la conversación entre Malintzin y Cortés, por un lado, y aquella entre Pizarro y Atahualpa, por el otro. Tomar estas escenas como figuraciones emblemáticas de la situación colonial significa leer en estos orígenes de la traducción colonial un paradigma histórico que requiere precisar la pregunta por un pasado que no es accesible sin traducción. Es desde entonces, desde un punto de vista americanista al menos, que se construye una historia de la traducción, que es bien diferente a la translatio romana. No solo traducir, sino igualmente teorizar desde entonces requiere pensar en constelaciones, las que dependiendo de la escena original se basan en diferentes configuraciones. Si partimos de la configuración que es figurada por la escena de Malintzin, podemos pensar la crisis de la traducción del modo en que prospectivamente se inscribirá en una modernidad caribeña. Es el ecuatoriano-mexicano Bolívar Echeverría quien con esta figura comienza su libro sobre la modernidad del barroco, que ciertamente no hubiese sido posible sin el aporte neobarroco caribeño. Dentro de la configuración principalmente caribeña, la traducción, aunque siempre alteración, es capaz de inscribir en la pérdida un exceso del código, una pérdida y violencia hasta cierto punto productiva. En el trascurso del argumento de Echeverría - argumento en el que no sorprende que mediante la noción del ethos también se refiera de manera central a la pregunta de un estilo de vida, a una crítica in actu, si es posible resumirlo de esta manera- encontramos una afirmación que a mi juicio es particularmente resistente, por no ser necesaria para la formulación

Revista Iberoamericana, Vol. LXXXI, Núm. 253, Octubre-Diciembre 2015, 939-953 
del proceso de la códigofagia y que, según mi lectura, se refiere a otra configuración de la traducción y que más bien encontraría su emblema en la conversación, ausente en todos los sentidos, entre Pizarro y Atahualpa. En vez de enfatizar continuamente la superación del código dominante por su exceso, como bien lo resume Severo Sarduy, justo antes de presentar su concepto de códigofagia, Echeverría constata que el mundo indígena ya no es rescatable. Si partimos de la configuración andina y su articulación de la crisis de la traducción, hay que partir de una escena según la cual, después de la conquista del Perú, la fuerza evocativa de la práctica simbólica siempre está amenazada por una pérdida no marcada, que no deja huellas, que no sobrevive. La traducción aquí siempre implica también una pérdida, nunca recupera, aunque sea de manera alterada, lo que fue y convierte lo traducido en la muestra de algo irrecuperable, justamente porque otro idioma estaba a disposición, un idioma que si bien es afectado por los cambios, no deja de ser otro y ello quiere decir: que es siempre más que una alteración de un código dominante. Si bien, bajo la constelación colonial de nuestra modernidad, la traducción siempre va acompañada de una pérdida, habrá que diferenciar la configuración de esa pérdida.

Se trata entonces de una pérdida algo diferente de la caribeña; y el caso de Bolívar Echeverría, quien no sólo se articula desde su exilio mexicano, sino también desde un México que le permite vivir su patria ecuatoriana, es revelador. Su resistencia a la ideología nacionalista mexicana, que más que todas las demás, como también lo nota Ángel Rama, intentó integrar su pasado indígena, esa resistencia de Echeverría, creo que no sólo es una crítica a las retóricas nacionalistas, sino que se debe a la experiencia de las naciones andinas. El fuerte énfasis en esa pérdida absoluta, una cierta desconfianza acerca del mestizaje y la lectura de una configuración de traducciones que nunca podrán realizarse sin violencia, estas son las condiciones previas desde las cuales Echeverría se propone revisar el paradigma barroco para las Américas. Es decir, en vez de articular otro barroco, o mejor dicho, en vez de seguir las políticas de los prefijos: caribe-barroco, andino-barroco, etc., es la totalidad contradictoria del término "barroco" la que expone en su revisión teórica. No son estos, sin duda, ejemplos de crítica y estudios andinos, pero sí de un enfoque teórico que podremos llamar transandino, ya que no se trata de teorizar lo andino, sino de revisar el plano teórico desde esta experiencia sin localizarlo, sin renunciar a una aspiración de "totalidad".

Para dar un ejemplo de una lectura de algo que no está en su traducción, quisiera recurrir a un ejemplo de la literatura colonial. ${ }^{1}$ El texto que quisiera comentar brevemente es un texto que en los años ochenta recibió una cierta atención para luego desparecer del debate. Se trata de un corto texto de José de Acosta con el título La peregrinación de

Para un estudio más a fondo de la literatura colonial, en específico la poesía lírica, con una perspectiva transandina ver la colaboración de Vicente Bernaschina Schürmann en este volumen.

Revista Iberoamericana, Vol. LXXXI, Núm. 253, Octubre-Diciembre 2015, 939-953 
Bartolomé Lorenzo. Sin duda, es este un texto que no se deja identificar tan fácilmente como un texto andino, tal como parece igualmente difícil e imposible excluirlo. No narra nada particularmente andino, aunque sí fue escrito en el Perú y su narración culmina en el Perú. Cuando fue reeditado, lo que se debatía entonces era ante todo la definición de lo literario. No sorprende entonces que el mismo Cornejo Polar presentara la edición de Petróleos del Perú de este texto. El debate que el siguiente prólogo de Arrom bien resume es la pregunta si este texto es o no literario, una pregunta que también Lienhard retomó y que como proyección final tiene la ambición de revisar el viejo dogma, articulado por Henríquez Ureña, que la novela es un género tardío en América Latina, identificando este corto texto como la primera novela latinoamericana.

Pero más que su estatus literario y la pregunta sin duda transandina, si éste es o no un texto peruano, es la narración misma la que es de interés, ya que implica, como momento fundacional, una transcripción, una traducción y eso en varios sentidos. Primero, el mismo Acosta se presenta como el cronista de una historia de un personaje supuestamente real, el cual, como Lienhard lo sugiere, pudiera ser perfectamente el alter ego de Acosta. Sea com sea, Acosta pretende transcribir un relato oral, lo ordena y lo articula, ya que su héroe, como él mismo reconoce, era persona "de pocas palabras" (29). Segundo y obviamente, se trata de una traducción a un plano alegórico de todo el viaje hacia las Américas, que en el mejor de los casos culmina en la conversión del héroe, transformando igualmente la conquista en un camino a la salvación de las Américas.

El viaje por excelencia, potencialmente transcultural así como fundacional y existente en todas las narraciones americanas y europeas, es el de la peregrinación. La peregrinación aquí funciona como la figura sincretista y alguien tan familiarizado con los mitos indígenas como el jesuita Acosta sin duda conocía las narraciones fundacionales de peregrinación que también la cultura andina conoce. Sin embargo, como era de esperarse, lo andino se borra cada vez más mientras avanza el texto y eso quiere decir literalmente: cada vez que el personaje principal se acerca más y más a la ciudad de Lima. El último párrafo de este relato, que es el único que nombra explícitamente a la ciudad de Lima, concluye de esta manera:

Con esto, sin dar más largas a su vocación [...], se vino a Lima con el Padre Cristóbal Sánchez y donde el Padre Provincial Portillo, le recibió por Hermano Coadjutor, admirándose él grandemente de que Nuestro Señor le trajese tanto bien, por tan grandes rodeos y trabajos, estimando la grande caridad que le hacen en la Compañía, donde ahora está empléadose [sic] en cuanto le manda la obediencia, con grande edificación. Sea Nuestro Señor alabado para siempre. Amén. (66)

Se ve claramente lo que este sincretismo significa: no es herramienta donde lo otro sobrevive, más bien lo borra. La peregrinación del hombre europeo que en la naturaleza americana se hace casi bestia, culmina en la superación de esta naturaleza.

Revista Iberoamericana, Vol. LXXXI, Núm. 253, Octubre-Diciembre 2015, 939-953 
De cierto modo, la culminación de la peregrinación en el plano alegórico prefigura lo que la teoría, la problemática teoría de la unidad, realiza como su camino, su método: borrar la contradicción.

Este texto, que como todos los textos de peregrinación produce una constante tensión entre el plano alegórico y el plano narrativo, revela esta tensión únicamente en la parte del Caribe, cuando el protagonista corre el riesgo de perderse en su camino, ser víctima de las contradicciones. Y esto nos lleva a otra tensión. Básicamente, en lo que se refiere al pasaje al Nuevo Mundo, el texto habla de dos estaciones: el Caribe y los Andes. Si los Andes son el punto final que al mismo tiempo prefigura un retorno, es decir, aquello donde la molesta naturaleza y sus habitantes ya no perturban el camino a la salvación, el Caribe y el viaje al Perú vía Panamá marcan, hasta en su plano físico, un espacio que permite la fuerte presencia de otro plano además del alegórico, por el simple hecho de ser una zona de pasaje, de cruce. Llegar al Perú como a la salvación resulta una llegada que borra en cierta medida lo que ahí ya estaba, se impone sobre algo de lo cual en el Caribe es más fácil olvidarse, aunque nunca ha dejado de marcar su presencia: lo precolombino. Llegar a lo que ya no es, es la inversión de la preocupación por un pasado irrecuperable. Es por ello que supongo que Echeverría desea completar el paradigma caribeño con este comentario acerca de un pasado definitivamente perdido. Esa pérdida que hasta cierto punto puede considerarse como una de las condiciones imprescindible para una reflexión transandina, figurando otro tipo de pérdida que la caribeña. En vez de hacer legible el exceso de los códigos, un constante inicio, se trata de recordar un regreso a algo que ya no es lo mismo, reconfigurando así la constelación de la teoría lingüística de la códigofagia desde una configuración andina y no sólo caribeña. La totalidad del proceso histórico también se nutre de esta experiencia, que formulada de este modo no es una teoría sobre lo andino, sino un paradigma de lectura para estas totalidades contradictorias que representan las traducciones de nuestra modernidad (colonial).

He sido quizás algo audaz al suponer una doble configuración en el argumento de Bolívar Echeverría; esta doble configuración, según mi lectura, se debe al hecho que bajo la constelación de la modernidad colonial y su lenguaje de códigofagia se subsumen dos configuraciones diferentes: la caribeña y la andina. Quisiera, a modo de conclusión, desarrollar un poco más la configuración andina con un autor que también fue la base para las reflexiones de Cornejo Polar: José María Arguedas.

Aunque sería más que apropiado releer un texto como El zorro de arriba y el zorro de abajo me voy a limitar, por razones de espacio, a unas pocas observaciones acerca de sus textos de antropología cultural. Es ahí donde comenta explícitamente su

Revista Iberoamericana, Vol. LXXXI, Núm. 253, Octubre-Diciembre 2015, 939-953 
proyecto narrativo, el de narrar la historia del Perú. No hay que dejarse irritar por una supuesta programática nacionalista que siempre va acompañada de una tal retórica. Lo que interesa en este contexto es el estatus paradigmático del Perú como cultura, como objeto y punto de partida para una teoría cultural.

¿En qué sentido? Si hablamos de naciones como el Perú, hablamos, según Arguedas, de culturas complejas, de culturas establecidas. Es importante notar este detalle, ya que se habla de culturas en un sentido muy preciso y que, por ejemplo, no se dejan describir a base de un conjunto de ciertas prácticas. Más bien, Arguedas habla de la cultura peruana como una entidad históricamente tan definida (no necesariamente unida u homogénea), que permite narrar su historia más allá de los hechos y las prácticas, es decir: narrar una historia que con sus narradores y sus perspectivas no sólo opera al nivel de una crítica (cultural), sino que gracias a su configuración específica permite una reflexión teórica. Las configuraciones andinas, para Arguedas, permiten vislumbrar una constelación de aquella totalidad contradictoria que Cornejo Polar nombró teoría. Es por ello que la narración peruana no tiene que limitarse a ser una historia encerrada en sí misma, sino que abre una visión sobre aquella constelación teórica que Arguedas llama, en 1952, el "estudio del hombre de cualquier nación del mundo":

La cultura de un imperio de este modo sustentada, en lo humano y en el medio geográfico [la cultura antigua peruana, PVO], no podía ser totalmente destruida por ninguna contingencia, por grave que fuera.

La organización administrativa del virreinato tuvo que adecuarse a la configuración del antiguo imperio. [...] El Perú constituye por esos mismos hechos, por esta realidad, un problema subyugante para los que se dedican al estudio del hombre de cualquier nación del mundo. ("El complejo"1)

Arguedas habla de una configuración del imperio incaico que nos obliga a revisar el uso del término "imperio”, es decir su constelación teórica. Imperio es aquí, primero, una noción más formal que histórica al referirse ante todo a una cualidad de una cultura. "Imperio" por ello no se limita al imperio español y tampoco al sólo acto de dominación. Como índice de una cultura "definida", subsume diferentes configuraciones que en su conjunto permiten una reflexión teórica sobre lo que es el hombre en tanto que ser cultural. Es a esa pregunta tan fundamental y al mismo tiempo no inmediatamente funcional a la que aspira el lujo de la teoría (Blumenberg) y que, con Arguedas, ha de pensarse como parte de un discurso teórico que se forma como una constelación. El aporte transandino, entonces, consistiría en narrar una configuración con una visión teórica, aspirando a una totalidad sin deshacerse de su especificidad. Un acto ciertamente algo contradictorio; pero sólo a primera vista. Porque en vez de alterar simplemente lo universal, en vez de realizar una simple variación, esta aspiración altera la misma noción de lo universal; lo cual, desde un punto de vista americanista, después de la

Revista Iberoamericana, Vol. LXXXI, Núm. 253, Octubre-Diciembre 2015, 939-953 ISSN 0034-9631 (Impreso) 
Conquista no puede referirse a la misma noción de universalidad de antes. La totalidad en nuestra modernidad colonial no puede ser sino contradictoria, ha de pensarse como una constelación y no como una unión; y sólo pensando la totalidad de este modo, si bien sigo el argumento de Cornejo Polar, es que la misma noción de totalidad se opone a una totalidad colonial. Ello también quiere decir: la constelación es histórica en cuanto narra la historia de las rupturas. Y en cuanto tal, es una narración bien diferente a la de las configuraciones, cuyas figuraciones aspiran a la consolidación. Como bien lo ha dicho Cornejo Polar respecto de la totalidad: desde nuestra perspectiva americanista, es nuestra misma historia la que nos obliga pensar una totalidad, una constelación que es algo más que una simple suma pluralista.

¿Ahora, por qué no mantener los términos particular y universal en este caso? Se trata de pensar la relación entre lo específico y lo general de otra manera, se trata de pensar un dualismo que no se reconcilia gracias a una integración y que tampoco se paraliza en una dicotomía, sino que permite un paralelismo relacionado. La configuración, por su lado, siempre es expresión crítica y su impulso crítico no se traduce del todo a un nivel "general" o a un tipo de reflexión que se refiere a una totalidad. La figuración requiere una relación concreta que no se deja formalizar completamente.

¿Y por qué no decir: en el fondo todo es configuración? La aspiración hacia lo universal representa, para Arguedas al menos, la única sobrevivencia posible de la cultura peruana actual. Es decir, no es posible sobrevivir culturalmente sólo con un gesto crítico local. Así lo afirma en su "Discurso para el Premio Inca Garcilaso de la Vega", publicado bajo el título "No soy un aculturado":

$[\ldots]$ intenté convertir en lenguaje escrito lo que era como individuo: un vínculo vivo, fuerte, capaz de universalizarse, de la gran nación cercada y la parte generosa, humana, de los opresores. El vínculo podía universalizarse, extenderse; se mostraba un ejemplo concreto, actuante. El cerco podía y debía ser destruido; el caudal de las dos naciones se podía y debía unir. Y el camino no tenía por qué ser, ni era posible que fuera únicamente el que se exigía con imperio de vencedores expoliadores, o sea: que la nación vencida renuncie a su alma, aunque no sea sino en la apariencia, formalmente, y tome la de los vencedores, es decir que se aculture. (12)

Más allá del caso peruano, esa pasión "universalizadora" es la que nos permite reformular y retomar el proyecto de una "teoría realmente nuestra". La localización de la narración europea, en los últimos años tan requerida (y acto que se encuentra ya en Arguedas cuando formaliza el término "imperio"), se agotaría en su gesto crítico si no es capaz de abrir al mismo tiempo un espacio teórico otro. Pero esa teoría, en el caso de Arguedas, sería transandina justamente por no ser del todo andina, y "nuestra" en el sentido que presupone haber pasado por "nuestra" historia sin quedarse en ella. El proyecto literario de Arguedas, el de "convertir el lenguaje escrito", lenguaje

Revista Iberoamericana, Vol. LXXXI, Núm. 253, Octubre-Diciembre 2015, 939-953 
tradicionalmente atribuido a una universalidad europea y su modo de teorizar, resume esta reflexión al ejecutar una conversio en el medio mismo de la conversio: la escritura. Aunque el lenguaje siempre es algo vivido e individual, no por ello ha de renunciar a su aspiración "universal". La condición colonial de nuestra modernidad no implica necesariamente una identificación inevitable de lo universal con lo colonial, sino que más bien obliga a repensar lo universal, si, desde entonces, toda universalización lograda y feliz mantiene un rasgo definitivo, justamente no por "aculturarse". Es por marcar explícitamente este giro crítico-teórico, este momento de intervención en el mismo discurso teórico, que propongo hablar de constelaciones en vez de universalidad.

Ángel Rama, en su introducción a la antología de textos antropológicos de Arguedas que fueron publicados bajo el título de Formación de una cultural nacional indoamericana, habla de un giro "culturalista", identificando de esa manera en el proyecto de Arguedas un proyecto que se exime de la dicotomía entre lo local y lo universal. Es -así lo afirma el crítico uruguayo- un indigenismo local el que es revisado por Arguedas. Identificar lo indigenista en Arguedas con una cuestión estrictamente local no es otra cosa, según Rama, que un malentendido de la "generación posmodernista latinoamericana" ("Introducción" XIV). Si el "indigenista" Arguedas habla de la cultura peruana como una cultura tan definida, que se resiste a cualquier contingencia, es efectivamente un malentendido leer sus propuestas formuladas como propuestas locales o, cito otra vez a Rama, “[c] omo en los ejemplos paralelos y contemporáneos del 'negrismo' antillano y del 'revolucionarismo" mexicano (...) [como] una formulación local, peculiar, referida a la problemática cultural de la región [...]” (XIV) Es más: hasta podría polemizarse que el afán universalizador para nada es ajeno al indigenismo, lo que equivale a decir que el indigenismo no es lo otro de lo transandino, sino su condición; hasta podríamos hablar de un indigenismo "transandino", ya que el mismo discurso indigenista presupone la condición colonial.

Si, como Ángel Rama lo afirma en ese mismo texto, Arguedas propone pensar más allá del regionalismo sin "por eso apartarse del movimiento" (XIV) y enfrentarse a una reflexión sobre la cultura que no se limita a su condición específica sin dejar de ser específica, podríamos ver en el giro "culturalista" de Arguedas, en el paso del indigenismo a una reflexión con "una dominante nota "culturalista" (XV), un giro transandino avant la lettre. Queda claro, entonces, que lo transandino no implica un más allá de lo andino o, aún menos, una especie de "post-andinismo". Más bien, el prefijo "trans" adquiere sentido como índice de una cierta reflexión teórica cuya especificidad se mantiene como una especificidad andina, hecha legible en otra parte, en otro idioma, en otro contexto. Importa la palabra "mantener", puesto que implica no sólo la voluntad de querer identificar algo, sino igualmente se refiere a una programática crítica: el mestizo, sujeto por excelencia de ese giro "culturalista”, interesa no sólo por su capacidad de adaptación, requisito perfectamente útil en tiempos de un mercado que

Revista Iberoamericana, Vol. LXXXI, Núm. 253, Octubre-Diciembre 2015, 939-953 ISSN 0034-9631 (Impreso) 
hábilmente nos convence de su universalidad por ser cada vez más ubicuo. Estudiar al mestizo tal como Arguedas lo describe implica -y es en ese sentido que el paradigma transandino puede reclamar igualmente una fuerza crítica y política- una búsqueda de lo que queda de todo aquello que no es occidental o colonial. Cito otra vez a Ángel Rama quien claramente vio la importancia de este aspecto del mestizo, "personaje sin cuarteles de nobleza como el indio, de escaso prestigio intelectual o ético, pero que vista su destreza, energía y capacidad de adaptación, se presentó como el más viable, el único capaz de salvar algo de la herencia india en los difíciles trances de la aculturación" (XVIII).

El giro "transandino" en Arguedas es entonces parte de una historia. Y el mismo Arguedas es claro en afirmarlo. La historia de su proyecto de "universalización" se debe a dos impulsos. El primero lo describe de la siguiente manera:

Fue leyendo a Mariátegui y después a Lenin que encontré un orden permanente en las cosas; la teoría socialista no sólo dio un cauce a todo el porvenir sino a lo que había en mí de energía, le dio un destino y lo cargó aún más de fuerza por el mismo hecho de encauzarlo. [...] fue la ideología socialista y el estar cerca de los movimientos socialistas lo que dio dirección y permanencia, un claro destino a la energía que sentí desencadenarse durante la juventud. ("No soy" 12-13)

El nivel de la teoría resulta no ser sólo una posibilidad, sino además una necesidad. El socialismo, como teoría, igualmente se transforma, se convierte en una constelación que trata de ver "un orden permanente en las cosas". Ese saber es necesario para la acción y el "lujo" de la teoría adquiere un valor político obvio. No tanto por las soluciones o las prescripciones que promete, sino por abrir un campo de acción.

El otro es el Perú, aquel espacio que en el texto sobre "El complejo cultural en el Perú" había sido nombrado una configuración:

El otro principio fue el de considerar siempre el Perú como una fuente infinita para la creación. Perfeccionar los medios de entender este país infinito mediante el conocimiento de todo cuanto se descubre en otros mundos. (13)

Entender al Perú equivale a entender lo concreto, no tanto la ley del antagonismo o su estructura formal, sino más bien cómo una historia se configura dentro de la historia. Es obvio que la segunda fuente no es lo concreto de la primera, sino que mantienen otro tipo de relación, que como en el caso de lo andino y lo transandino, o dicho de manera más formal, como en el caso de la constelación y la configuración, son más bien dos perspectivas que, sin fundirse, se presuponen. Es, como lo he sugerido ya, una relación que también se puede aplicar a la relación entre crítica y teoría. El discurso americanista que tanto aspiró a tener una "teoría realmente nuestra" siempre

Revista Iberoamericana, Vol. LXXXI, Núm. 253, Octubre-Diciembre 2015, 939-953 
fue rico en cuanto crítico, pero, según Cornejo Polar, tuvo que fracasar con su teoría. Si entendemos teoría como la otra mirada de nuestra crítica y como la tarea de leer las constelaciones de la teoría con nuestras configuraciones críticas a lo mejor no tenemos que temer de quedarnos sin una "teoría realmente nuestra". Es ahí, según mi lectura, donde reside el potencial de lo transandino, de algo que nace en y con aquella parte del mundo, que no sólo nos invita a pensar y vivir una configuración otra, sino, además con sus otras estrellas, a pensar nuestra teoría como constelación. Pero tratándose de una constelación, una "teoría realmente nuestra" no es nuestra gracias a un principio de identidad. Entonces la utopía de Arguedas, tantas veces citada por Cornejo Polar, también incluye un lado menos optimista. Si podemos vivir en una patria todas las patrias, no es porque una patria es todas las patrias, sino porque sabemos lo que significa volver a algo que ya no es.

\section{BiBLIOGRAFÍA}

Acosta, José de. La peregrinación de Bartolomé Lorenzo. Lima: Petroleros del Perú, 1982.

Arguedas, José María. "El complejo cultural en el Perú". Formación de una cultura nacional indoamericana. México: Siglo XXI, 1989. 1-8.

"No soy un aculturado...". El zorro de arriba y el zorro de abajo. Caracas: Horizonte, 2006. 11-13.

Benjamin, Walter. Ursprung des deutschen Trauerspiels. Frankfurt: Suhrkamp, 2000. Blumenberg, Hans. Theorie der Unbegrifflichkeit. Frankfurt: Suhrkamp, 2007.

Cornejo Polar, Antonio. "Literatura peruana: Totalidad Contradictoria". Revista de Crítica Literaria Latinoamericana 18 (1983): 37-50.

"Para una teoría literaria hispanoamericana: A veinte años de un debate decisivo". 1992. Revista de Crítica Literaria Latinoamericana 25 (1999): 9-12.

Echeverría, Bolívar. La modernidad de lo barroco. México D.F.: ERA, 1998.

Mignolo, Walter. "Entre el canon y el corpus. Alternativas para los estudios literarios y culturales en y sobre América Latina”. Nuevo Texto Crítico 7.14/15 (1995): 23-36.

Rama, Ángel. "Introducción". Formación de una cultura nacional indoamericana. José María Arguedas. México: Siglo XXI, 1989. IX-XXIV.

Valdivia Orozco, Pablo. "Configuraciones del convivir: algunos apuntes sobre el cruce teórico de la novela y el Caribe”. TransitAreas. Convivencias en Centroamérica y el Caribe. Ottmar Ette, Gesine Müller, Alexandra Ortiz Wallner, eds. Frankfurt/ Madrid: Vervuert, 2011. 216-30.

Revista Iberoamericana, Vol. LXXXI, Núm. 253, Octubre-Diciembre 2015, 939-953 
